\title{
THE RELATIONSHIP BETWEEN PARENTING STYLE AND CHILDREN LEARNING DISCIPLINE
}

\author{
Nurhadi \\ Sekolah Tinggi Agama Islam Al-Azhar Pekanbaru, Riau, Indonesia \\ Email: alhadijurnal@gmail.com \\ Fatmayanti \\ Sekolah Tinggi Agama Islam Al-Azhar Pekanbaru, Riau, Indonesia \\ Email: fatmayanti@gmail.com \\ DOI: 10.35445/alishlah.v12.i2.199 \\ Accepted: June $10^{\text {th }}, 2020$. Approved: August $10^{\text {th }}, 2020$ \\ Published: December $30^{\text {th }}, 2020$
}

\begin{abstract}
The purpose of this study is to determine parenting as applied by parents in Kelurahan Rawang Empat and to what extent parents' understanding of the relationship between parenting and children's learning discipline, as well as the causes of parenting. This research uses descriptive method with correlational research analysis techniques. Based on the analysis conducted showed that in the Rawang Empat sub-district Bandar Petalangan sub-district Pelalawan District parenting patterns in primary school children with an average value of 27.43 included in the category of "good enough" which is in the interval 25-28. While the level of discipline of elementary school children with an average value of 23.13 is included in the category of "sufficient discipline" that is at intervals of 21-23. By using product moment correlation analysis the results of hypothesis analysis show that the value of rxy $=0.953$ is in a positive direction. The relationship between parenting style and the level of discipline of learning of elementary school children is included in the category of "very strong" at intervals of 0.80-1,000. The research data also showed that tcount $=14.416$, while ttable at a significance level of $5 \%=0.433$ and ttable at a significance level of $1 \%=0.549$. It can be seen that tcount is greater than ttable. Thus it can be concluded that there is a significant relationship between parenting and the level of discipline of elementary school children in Rawang Empat Village, Bandar Petalangan District, Pelalawan Regency.
\end{abstract}

Keywords: Relationship, Parenting, Parents, Learning Discipline 


\title{
HUBUNGAN POLA ASUH ORANG TUA DENGAN KEDISIPLINAN BELAJAR ANAK
}

\begin{abstract}
Abstrak
Tujuan penelitian ini adalah untuk mengetahui pola asuh seperti apa yang telah diterapkan oleh orang tua di Kelurahan Rawang Empat, serta seberapa jauh pemahaman orang tua tentang hubungan pola asuh dengan kedisiplinan belajar anak, juga penyebab pola asuh orang tua. Penelitian ini menggunakan metode deskriptif dengan teknik analisis penelitian korelasional. Berdasarkan analisa yang dilakukan menunjukkan bahwasanya di kelurahan Rawang Empat kecamatan Bandar Petalangan Kabupaten Pelalawan pola asuh orang tua pada anak sekolah dasar dengan nilai rata-rata 27,43 termasuk ke dalam kategori “ cukup baik" yaitu berada pada interval 25-28. Sedangkan tingkat kedisplinan anak sekolah dasar dengan nilai rata-rata 23,13 termasuk dalam kategori "cukup disiplin" yaitu berada pada interval 21-23. Dengan menggunakan analisis korelasi product moment hasil dari analisis hipotesis memperlihatkan bahwa nilai $r_{x y}=0,953$ berada pada arah yang positif. Hubungan pola asuh orang tua dengan tingkat kedisiplinan belajar anak sekolah dasar termasuk dalam kategori "sangat kuat" pada interval 0,80-1,000.Data penelitian juga menunjukkan bahwa $t_{\text {hitung }}=$ 14,416, sedangkan $t_{\text {tabel }}$ pada taraf signifikansi $5 \%=0,433$ dan $t_{\text {tabel }}$ pada taraf signifikansi $1 \%=0,549$. Dapat dilihat bahwa $t_{\text {hitung }}$ lebih besar dari $t_{\text {tabel. }}$. Dengan demikian dapat diambil kesimpulan bahwasanya ada hubungan yang signifikan antara pola asuh orang tua dengan tingkat kedisiplinan anak sekolah dasar di Kelurahan Rawang Empat Kecamatan Bandar Petalangan Kabupaten Pelalawan.
\end{abstract}

Kata Kunci: Hubungan, Pola Asuh, Orang Tua, Kedisiplinan Belajar.

\section{PENDAHULUAN}

Pendidikan dibagi menjadi 3 macam yaitu pendidikan formal, nonformal, dan informal (Suprijanto,2009). Pendidikan formal merupakan pendidikan yang berjenjang dan berstruktur yang terdiri dari pendidikan dasar, menengah, dan pendidikan tinggi. Pendidikan nonformal merupakan jalur pendidikan luar sekolah, seperti kursus, seminar, dan pelatihan.

Pendidikan formal seperti di sekolah, sekolah memiliki peranan untuk mendidik siswanya. Setiap sekolah memiliki tata tertib yang wajib dipatuhi oleh setiap warga sekolah. Keluarga merupakan tempat belajar pertama untuk anak sebelum berbaur dan berinteraksi dengan masyarakat. Sikap dan tingkah laku orang tua akan berpengaruh pula pada sikap anak ketika nanti berinteraksi dengan masyarakat. Hendaklah orang tua senantiasa mendidik dan mengasuh anak dengan baik dan sesuai dengan ajaran islam. Dalam Islam peran orang tua sangatlah penting dalam membantu pertumbuhan fisik dan perkembangan psikis anaknya dan juga membebaskan anaknya dari siksaan api neraka. Sebagaimana firman Allah swt "Hai orang-orang yang beriman, peliharalah dirimu dan keluargamu 
dari api neraka yang bahan bakarnya adalah manusia dan batu; penjaganya malaikat-malaikat yang kasar, keras, dan tidak mendurhakai Allah terhadap apa yang diperintahkan-Nya kepada mereka dan selalu mengerjakan apa yang diperintahkan". (Q.S. at-Tahrim: 6).

Setiap orang tua memiliki caranya masing-masing dalam mengasuh dan mendidik anaknya. Ada orang tua yang mengasuh dengan penuh ketegasan, ada pula yang memberikan kebebasan kepada anaknya, serta ada pula orang tua yang senantiasa mendukung dan membimbing anaknya selagi apa yang dilakukan anak tersebut termasuk dalam kategori baik. Semua yang dilakukan orang tua tidak lain untuk melihat anaknya bahagia dan menjadi anak yang baik. Anak yang biasa dalam berbuat kebaikan akan membentuk karakter yang baik pula, salah satunya disiplin.

Hal yang mendorong peneliti dalam masalah ini sebab masih terdapat anak yang kurang disiplin, bahkan cukup signifikan, orang tua masih kurang paham akan hubungan pola asuh yang diterapkan dengan kedisiplinan anak. Disiplin merupakan salah satu faktor untuk meraih kesuksesan. Sebatas pencarian referensi yang peneliti temukan, belum ada yang membahas secara langsung dampak pola asuh orang tua kepada anak dalam meraih keberhasilan anak dalam prestasi.

Berdasarkan gejala-gejala dan fenomena tersebut, peneliti termotivasi dalam melakukan penelitian dengan membahas "Hubungan Pola Asuh Orang tua dengan Kedisiplinan Belajar Anak pada Sekolah Dasar", terutama di Kelurahan Rawang Empat Kec. Bandar Petalangan Kab. Pelalawan, yang tingkat keberhasilan anak terhadap pola asuh orang tua sebagai bahagian faktornya, maka hal ini sangat penting untuk diteliti, untuk mencari solusi dari permasalahan yang ada.

Dari beberapa pendapat para ahli ditarik kesimpulan bahwa pola asuh orang tua adalah bagaimana cara dari orang tua dalam mendidik anaknya baik secara langsung maupun tidak langsung. Secara terperinci pola asuh orang tua dapat diartikan sebagai suatu proses interaksi orang tua, yang meliputi kegiatan dengan anak yang meliputi berbagai kegiatan seperti, membimbing, memelihara, mendidik, serta mendisiplinkan dengan tujuan agar mencapai proses kedewasaan baik itu secara langsung atau tidak langsung.

Menurut Hourlock (Thoha, 1996) menjelaskan ada 3 jenis pola asuh orang tua yaitu sebagai berikut: a). Pola Asuh Otoriter; b). Pola Asuh Demokratis; c). Pola Asuh Permisif. Menurut Baumrind (Dariyo,2004) membagi jenis pola asuh menjadi 4 yaitu sebagai berikut: a). Pola Asuh Otoriter (parent oriented); b). Pola Asuh Permisif; c). Pola Asuh Demokratis; d). Pola Asuh Situasional. Menurut (Yatim dan Irwanto, 1991) terdapat tiga jenis dari pola asuh yaitu sebagai berikut: a). Pola Asuh Otoriter; b). Pola Asuh Demokratis; c). Pola Asuh Permisif. Menurut (Hardy dan Heyes, 1986) terdapat empat macam jenis dari pola asuh, 
Al-Ishlah: Jurnal Pendidikan - ISSN: 2087-949o (p); 2597-940X (e)

Vol. 12, No. 2 (2020)

yakni sebagai berikut: a). Autokratis (Otoriter); b). Demokratis; c). Permisif; d). Laissez faire.

Dengan begitu dapat diambil kesimpulan bahwa pada dasarnya terdapat 3 jenis pola asuh orang tua yaitu pola asuh otoriter, pola asuh demokratis, dan pola asuh permisif. Hal ini sesuai dengan pendapat beberapa ahli seperti yang dikatakan Hourlock yaitu pola asuh otoriter, demokratis, dan permisif. Adapun penjelasan lebih lanjut tentang ketiga jenis pola asuh di atas yaitu: 1). Pola Asuh Otoriter. Di kemukakan oleh (Dariyo, 2011) bahwa pola asuh otoriter adalah sentral yang artinya segala perkataan, ucapan, ataupun kehendak orang tua dijadikan patokan (acuan) yang harus dipatuhi oleh anaknya; 2). Pola Asuh Demokratis. Seperti yang dikemukakan oleh (Dariyo, 2011)bahwa pola asuh demokratis merupakan gabungan antara pola asuh otoriter dan permisif yang bertujuan untuk menyeimbangkan pemikiran tindakan dan sikap antara orang tua dan anak; 3). Pola Asuh Permisif. Dariyo (2011) mengemukakan pola asuh permisif yaitu dimana orang tua justru merasa tidak peduli dan cenderung memberikan kebebasan yang luas kepada anak-anaknya.

Menurut pendapat Hourlock (1999) faktor yang berpengaruh pada pola asuh orang tua yaitu karakteristik orang tua yang dapat berupa: a). Kepribadian orang tua; b). Keyakinan; c). Persamaan dengan pola asuh yang diterima orang tua; d). Penyesuaian dengan cara disetujui kelompok; e). Jenis kelamin; f). Usia orang tua; g). Jenis kelamin anak; h). Usia anak; i). Temperamen; j). Kemampuan anak; k). Situasi.

Menurut Manurung (1995) faktor-faktor yang mempengaruhi pola asuh orang tua yaitu sebagai berikut: a). Hal yang melatar belakangi pola pengasuhan orang tua; b). Tingkat pendidikan orang tua; c). Status ekonomi; d). Pekerjaan orang tua. Sedangkan Santrock (1995) menyebutkan ada beberapa faktor yangmempengaruhi dalam pola pengasuhan antara lain: a). Penurunan cara mengasuh yang didapat sebelumnya; b). Perubahan budaya, yaitu dalam hal nilai, norma serta adat istiadat antara dulu dan sekarang.

Definisi disiplin dapat disimpulkan sebuah keadaan yang terbentuk dari sebuah proses dalam latihan yang dikembangkan menjadi serangkaian perilaku yang di dalamnya terdapat unsur-unsur ketertiban, kesetiaan, ketaatan kepatuhan dimana semua itu dilakukan sebagai bentuk dari tanggung jawab yang memiliki tujuan untuk mawas diri.

Tujuan membentuk sikap disiplin pada anak yaitu : 1) membantu anak agar mampu berdiri sendiri atas tanggung jawab sendiri, 2) menciptakan situasi yan tertib dalam kegiatan belajar dan mengajar. Berikut ini yang merupakan fungsi disiplin yaitu: a). Menata kehidupan bersama; b). Membangun kepribadian; c). Melatih kepribadian; d). Menciptakan situasi yang kondusif. 
Dengan begitu belajar dapat diartikan sebagai proses berubahnya tingkah laku individu melalui interaksi dengan lingkungan, dengan begitu jelaslah tujuan dari belajar itu prinsipnya sama yaitu perubahan tingkah laku.

Berdasarkan makna dari kata disiplin dan kata belajar di atas maka dapat ditarik kesimpulan bahwa disiplin belajar adalah perbuatan dan sikap siswa saat melakukan kewajiban belajar secara sadar yaitu dengan menaati peraturan yang ada di lingkungan rumah maupun lingkungan sekolah.

Salah satu ilmu yang diajarkan dalam agama islam yaitu sikap disiplin. Disiplin sangat diperlukan dalam kehidupan sehari-hari karena sikap disiplin ini sangatlah berpengaruh pada kesuksesan di masa depan. Kedisiplinan dan kelembutan adalah hal yang diajarkan dalam agama islam. Seperti contoh, waktu shalat fardhu yang memiliki batas waktu awal dan akhir, dengan begitu umat muslim haruslah shalat tepat pada waktu yang telah ditentukan, kalau tidak maka shalatnya dianggap tidak sah. Disiplin juga merupakan sifat orang yang bertakwa.

\section{METODE PENELITIAN}

Penelitian ini termasuk penelitian kuantitatif dengan menggunakan metode deskriptif menggunakan teknik analisis penelitian korelasional. Studi korelasi bertujuan untuk menguji hipotesis, dilakukan dengan mengukur sejumlah variabel kemudian menghitung koefisien korelasi dari variabel-variabel tersebut, agar dapat ditentukan variabel mana yang berkorelasi. Penelitian ini dilaksanakan selama empat bulan mulai dari bulan Desember 2019 sampai dengan bulan Maret 2020.Tempat Penelitian ini dilaksanakan di Desa Rawang Empat Kecamatan Bandar Petalangan Kabupaten Pelalawan. Subjek dari penelitian ini adalah Para Orang Tua yang memiliki anak yang sedang duduk di bangku sekolah dasar (SD). Objek penelitian ini adalah Hubungan pola asuh orang tua dengan kedisiplinan belajar anak SD di Desa Rawang Empat Kecamatan Bandar Petalangan Kabupaten Pelalawan. Populasi penelitian adalah semua orang tua yang memiliki anak yang sedang duduk di bangku sekolah dasar. Populasi ini berjumlah 150 orang. Pada penelitian ini jumlah populasinya lebih dari 100, maka peneliti mengambil sampel sebanyak $15 \%$ dari total populasi yang ada yaitu sebanyak 23 orang.

Data-data yang diperlukan dalam penelitian ini dikumpulkan dan diperoleh melalui observasi, angket, dan wawancara. Peneliti menggunakan teknik analisis korelasi. Tahapan analisisnya sebagai berikut:

\section{Analisis Pendahuluan}

Menganalisis tentang hubungan pola asuh orang tua dengan kedisiplinan belajar anak sekolah dasar di Kelurahan Rawang Empat Kecamatan Bandar Petalangan Kabupaten Pelalawan dalam bentuk angka (kuantitatif), langkah yang diambil dalam mengubah data kualitatif menjadi kuantitaif adalah dengan 
Al-Ishlah: Jurnal Pendidikan - ISSN: 2087-949o (p); 2597-94oX (e)

Vol. 12, No. 2 (2020)

memberi nilai pada setiap poin jawaban pada pertanyaan angket (Moleong, 2006: $85)$.

a. Penskoran

Tabel 1Tabel Skor Jawaban Angket Pola Asuh Orang Tua dan Kedisiplinan Belajar Anak

\begin{tabular}{llllll}
\hline Simbol & $\begin{array}{l}\text { Kategori Jawaban } \\
\text { Pola Asuh }\end{array}$ & Skor & Simbol & $\begin{array}{l}\text { Kategori } \\
\text { jawaban } \\
\text { Kedisiplinan }\end{array}$ & $\begin{array}{l}\text { Sk } \\
\text { or }\end{array}$ \\
\hline A & Demokrasi & 3 & A & Sangat Disiplin & 3 \\
B & Otoriter & 2 & B & Disiplin & 2 \\
C & Permisif & 1 & C & Kurang Disiplin & 1 \\
\hline
\end{tabular}

b. Langkah selanjutnya kemudian mencari data (Moleong, 2006: 85):

1) Mencari lebar interval

$$
\begin{aligned}
& \mathbf{I}=\mathbf{R} \div \mathbf{K} \\
& \text { Dimana : } \\
& \mathbf{R}=\mathbf{H}-\mathbf{L} \\
& \mathbf{K}=\mathbf{I}+\mathbf{3 , 3} \log \mathbf{N}
\end{aligned}
$$

Keterangan:

$\mathrm{I}=$ Lebar interval $\mathrm{H} \quad=$ Nilai tertinggi

$\mathrm{L}=$ Nilai terendah $\mathrm{R}$ = Jarak pengukuran

$\mathrm{N}=$ Responden $\mathrm{K} \quad$ Jumlah interval

2) Mencari Mean dan Standar Deviasi

a) Mencari Variabel $\mathrm{X}, \bar{X}=\frac{\sum x}{N}$

b) Mencari Variabel $\mathrm{Y}, \overline{\mathrm{Y}}=\frac{\sum y}{N}$

c) Standar Deviasi SD =

$$
S=\sqrt{\frac{\sum x^{2-\frac{\left(\sum x\right)^{2}}{N}}}{N-1}} \text { dan } S=\sqrt{\frac{\sum y^{2-\frac{\left(\sum y\right)^{2}}{N}}}{N-1}}
$$

Keterangan:

$\bar{X}=$ Mean variabel $\mathrm{X} \quad \mathrm{S}=$ Standar Deviasi Populasi

$\bar{Y}=$ Mean variabel $Y$

3) Menentukan kualitas dari variabel, dengan menggunakan standar skala lima dari Gronlund (Moleong, 2006: 85):

a) $M+1,5 S D$ kriteria baik sekali 

b) $M+0,5 S D$ kriteria baik
c) $M-0,5 S D$ kriteria sedang
d) $M-1,5 S D$ kriteria kurang.

\section{Analisis Uji Hipotesis}

Analisis ini digunakan untuk menguji hipotesis yang peneliti ajukan yaitu dengan cara perhitungan lebih lanjut dengan analisis statistik (Moleong, 2006: 8586). Analisis statistik yang digunakan adalah analisis korelasi yaitu untuk mengetahui hubungan antara variabel bebas dan variabel terikat. Langkah-langkah yang ditempuh dalam uji hipotesis adalah:

a. Mencari korelasi antara variabel bebas (x) dengan variabel terikat (y), dengan rumus teknik korelasi Pearson Product Moment, sebagai berikut:

$$
\begin{aligned}
& \mathrm{r}_{\mathrm{xy}}=\frac{N \cdot \sum X Y-\left(\sum X\right)\left(\sum Y\right)}{\left.\sqrt{\left\{\left(N \cdot \sum X^{2}\right.\right.}-\left(\sum X\right)^{2}\right)\left(N \cdot \sum Y^{2}-\left(\sum Y\right)^{2}\right\}} \\
& \text { dimana: } \\
& \mathrm{r}_{\mathrm{xy}} \quad=\text { korelasi } \mathrm{x} \text { dan } \mathrm{y} \quad \mathrm{n} \quad \text { = jumlah sampel } \\
& \mathrm{x} \quad=\text { pola asuh orang tua } \quad \mathrm{y} \quad=\text { kedisiplinan anak }
\end{aligned}
$$

Nilai $\mathrm{r}$ yang sudah diperoleh dari rumus korelasi product moment selanjutnya akan dikonsultasikan dengan tabel interprestasi nilai $r$ berikut ini :

Tabel 2 Interprestasi Koefisien Korelasi Nilai $\mathbf{r}$

\begin{tabular}{cc}
\hline Interval Koefisien & Tingkat Hubungan \\
\hline $\mathbf{0 , 8 0}-\mathbf{1 , 0 0 0}$ & Sangat Kuat \\
$\mathbf{0 , 6 0}-\mathbf{0 , 7 9 9}$ & Kuat \\
$\mathbf{0 , 4 0}-\mathbf{0 , 5 9 9}$ & Cukup Kuat \\
$\mathbf{0 , 2 0}-\mathbf{0 , 3 9 9}$ & Rendah \\
$\mathbf{0 , 0 0}-\mathbf{0 , 1 9 9}$ & Sangat Rendah \\
\hline
\end{tabular}

b. Selanjutnya untuk mengetahui variabel $\mathrm{X}$ terhadap $\mathrm{Y}$ dapat ditentukan dengan rumus koefisien diterminan sebagai berikut:

$$
\mathrm{KP}=\mathrm{r}^{2} \times 100 \%
$$

$\mathrm{KP}=$ nilai koefisien determinan $\quad \mathrm{r} \quad=$ nilai koefisien

korelasi

Besar kecilnya koefisien korelasi dan tingkat keeratan yang sudah diperoleh tidak memiliki arti apapun sebelum dilakukan pengujian koefisien korelasi. Dengan demikian pengujian koefisien korelasi dilakukan untuk mengetahui berarti tidaknya hubungan antara variabel yang diteliti hubungannya. 
Vol. 12, No. 2 (2020)

c. Kemudian menguji signifikasi hubungan variabel $\mathrm{X}$ dengan $\mathrm{Y}$ dengan rumus:

$$
\begin{aligned}
& \mathbf{t}_{\mathbf{h}}=\frac{r \sqrt{n-2}}{\sqrt{1-r^{2}}} \\
& \text { dimana: } \\
& \mathrm{t}_{\mathrm{h}} \quad=\text { uji signifikasi korelasi } \mathrm{x} \text { dan } \mathrm{y} \quad \mathrm{r}=\text { korelasi } \mathrm{x} \text { dan } \mathrm{y} \\
& \mathrm{n} \quad=\text { jumlah sampel }
\end{aligned}
$$

d. Menguji apakah korelasi itu signifikan atau tidak dengan taraf signifikan 5\% atau $1 \%$.

\section{Analisis Lanjut}

Analisis lanjut adalah analisis lanjutan yang didasarkan pada analisis penelitian (analisis uji hipotesis). Analisis ini digunakan untuk membuat interpretasi lebih lanjut dari hasil hipotesis. Analisis ini digunakan dengan jalan mengkonsultasikan nilai $\mathrm{t}_{\mathrm{h}}\left(\mathrm{t}_{\text {hitung }}\right)$ dengan $\mathrm{t}_{\mathrm{t}}\left(\mathrm{t}_{\text {tabel }}\right)$ pada taraf signifikan $5 \%$ atau 1\% dengan kemungkinan (Moleong, 2006: 85-330):

a. Apabila nilai $t$ hitung yang diperoleh $>t$ tabel maka $\mathrm{H}_{\mathrm{a}}$ diterima dan $\mathrm{H}_{\mathrm{o}}$ ditolak. Berarti "ada hubungan antara pola asuh orang tua dengan kedisiplinan belajar anak sekolah dasar di Kelurahan Rawang Empat Kecamatan Bandar Petalangan Kabupaten Pelalawan”.

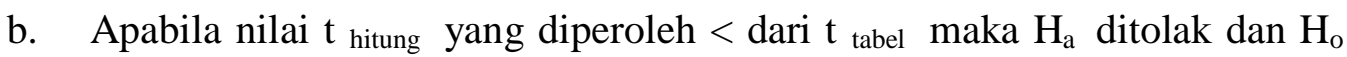
diterima. Berarti "tidak ada hubungan antara pola asuh orang tua dengan kedisiplinan belajar anak sekolah dasar di Kelurahan Rawang Empat Kecamatan Bandar Petalangan Kabupaten Pelalawan”.

\section{HASIL PENELITIAN DAN PEMBAHASAN}

\section{Deskripsi Lokasi Penelitian}

\section{Sejarah Kelurahan}

Kelurahan Rawang Empat sebelumnya merupakan sebuah desa yang ada di Kabupaten Pelalawan yang sebelumnya juga termasuk ke dalam wilayah Kabupaten Kampar, sebelumnya desa Lubuk Keranji berstatus Desa, Rawang Empat merupakan suatu wilayah perbatinan yang ada dalam wilayah kekuasaan kerajaan Pelalawan yang di sebuat dengan wilayah perbatinan Bunut. Setelah Proklamasi kemerdekaan Indonesia di Proklamirkan pada tanggal 17 Agustus 1945 maka tanggal 28 Oktober 1945, Raja Pelalawan terakhir menyatakan Kerajaan Pelalawan meleburkan diri ke dalam Negara Kesatuan Repulik Indonesia maka Perbatinan Bunut secara otomatis juga masuk kedalam wilayah Negara Republik Indonesia.

Kelurahan Rawang Empat di bentuk berdasarkan Peraturan Daerah Kabupaten Pelalawan nomor: 12 Tahun 2012 tentang pemekaran dan perubahan status Desa menjadi Kelurahan di Ibu Kota Kecamatan. Pada tanggal 5 Februari 
Al-Ishlah: Jurnal Pendidikan - ISSN: 2087-949o (p); 2597-940X (e)

Vol. 12, No. 2 (2020)

2014 Desa Lubuk Keranji diresmikan oleh Bupati Pelalawan menjadi Kelurahan Rawang Empat dengan luas wilayah $16,9 \mathrm{~km}^{2} \mathrm{Ha}$, yang saat ini dengan jumlah penduduk 1.327 jiwa yang terdiri dari 3 (tiga) lingkungan, 5 (lima) lingkungan warga dan 10 (sepuluh) Rukun Tetangga, dengan batas-batas wilayah sebagai berikut: a). Utara berbatas dengan Desa Sialang Godang; b). Selatan berbatas dengan Desa Kuala Semundam; c). Timur berbatas dengan Pondok 4 LRE PT. Serikat Putra; d). Barat berbatas dengan Desa Lubuk Terap.

\section{Kondisi Wilayah}

Kelurahan Rawang Empat dengan luas $16,9 \mathrm{~km}^{2}$ dan jika dipersentasekan $\pm 95 \%$ merupakan wilayah dataran dengan mencakup 3 (tiga) lingkungan, 5 (lima) Rukun Warga dan 10 (sepuluh) Rukun Tetangga yang terbagi atas beberapa karakteristik yaitu: adanya daerah daratan dan aliran sungai. Di sisi lain Kelurahan Rawang Empat juga pada musim kemarau sangat sulit untuk mendapat air bersih, kondisi ini memang bertolak belakang dengan kondisi wilayah yang berada di daerah daratan, semua ini akibat Pembukaan lahan perkebunan yang dilakukan oleh masyarakat sehingga rawa-rawa yang selama ini berfungsi menampung dan menahan air kini sudah menjadi darat.

Pada kondisi ini Kelurahan Rawang Empat sebagai Ibu Kota Kecamatan Bandar Petalangan berada di tengah-tengah perumahan masyarakat sehingga memudahkan masyarakat untuk berurusan, yang panjangnya $\pm 8 \mathrm{~km}$ mulai dari batas Desa Kuala Semundam sampai batas Desa Sialang Godang.

\section{Keadaan Alam}

Kelurahan Rawang Empat terletak di jalur khatulistiwa dengan iklim panas memiliki kondisi Geografis pada ketinggian 10 - 15 meter dari permukaan laut dengan struktur tanah dataran rendah (rawa) serta sebagian dataran dengan kondisi kering berbukit dengan kondisi curah hujan 5,582,5 Mm / tahun. Keadaan alam yang demikian membuat Kelurahan Rawang Empat tempat yang cocok untuk tumbuhan jenis tanaman perkebunan kelapa sawit dengan karet. Disini terdapat pula perusahaan perkebunan yang beroperasi dalam wilayah Kelurahan Rawang Empat yaitu PT. Serikat Putra di sekitar Kelurahan Rawang Empat. Masyarakat petani yang dulunya mengutamakan bercocok tanam jenis tanaman pangan kini sebagian besar sudah berubah ke jenis tanaman perkebunan.

\section{Sosial Budaya}

Penduduk Kelurahan Rawang Empat yang heterogen berasal dari seluruh wilayah yang ada di Negara Republik Indonesia terdiri dari suku, budaya, dan adat istiadat yang berbeda telah melahirkan Seni Budaya namun demikian masyarakat Kelurahan Rawang Empat dapat hidup berdampingan dengan harmonis. 
Vol. 12, No. 2 (2020)

\section{Jarak Geografis}

Mengenai jarak ke tempat-tempat umum dan pusat pemerintahan kecamatan tidak sampai $1 \mathrm{KM}$, ke ibukota kabupaten $55 \mathrm{KM}$, ke ibukota provinsi $420 \mathrm{KM}$, ke polresta $55 \mathrm{KM}$, ke pasar Sialang Godang $4 \mathrm{KM}$, ke sungai 0, 2 KM.

\section{Deskripsi Data}

Untuk menganalisis data penelitian yang sudah diperoleh dan mengkaji hipotesis, penelitian ini menggunakan teknik statistik yaitu analisis korelasi dengan rumus product moment. Karena jenis penelitian ini merupakan penelitian kuantitatif dengan menggunakan metode korelasi, yaitu penelitian yang melibatkan hubungan satu atau lebih variabel dengan satu atau lebih variabel lain. Variabel-variabel dalam penelitian dihubungkan pada satu kelompok responden, hubungan variabel yang ada dalam penelitian ini berbentuk bivariat, yaitu hubungan yang melibatkan satu variabel bebas (variabel X) dan satu variabel terikat (variabel Y). Hubungan bivariat itu dapat digambarkan sebagai berikut:

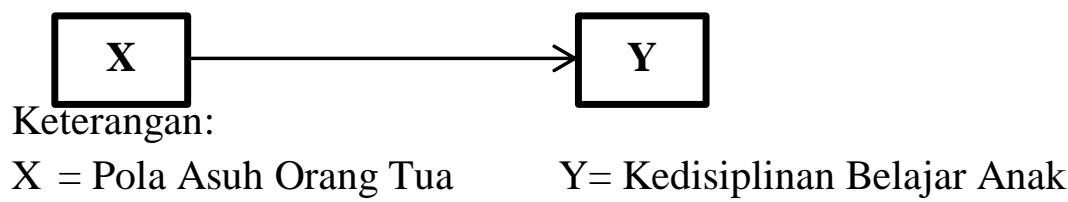

Secara garis besar penelitian ini dibagi menjadi dua tahap yaitu:

1. Tahap Persiapan

a. melakukan observasi

b. menyusun kisi-kisi instrumen angket

c. menyusun instrumen angket

d. mengkonsultasikan kepada Bapak Lurah dan para staf di kelurahan mengenai jadwal pelaksanaan penelitian

2. Tahap Pelaksanaan

a. Peneliti mengunjungi ke rumah responden untuk membagikan kuesioner

b. Peneliti menjelaskan petunjuk pengisian kuesioner kepada para responden

c. Peneliti membimbing para responden dalam pengisian kuesioner

\section{Analisis Data}

Untuk mengetahui hubungan pola asuh orang tua dengan kedisiplinan belajar anak sekolah dasar di Kelurahan Rawang Empat Kecamatan Bandar Petalangan Kabupaten Pelalawan, maka akan dilakukan pengujian hipotesis dengan tahapan-tahapan sebagai berikut: 
Al-Ishlah: Jurnal Pendidikan - ISSN: 2087-949o (p); 2597-940X (e)

Vol. 12, No. 2 (2020)

\section{Analisis Pendahuluan}

Dalam analisis ini berisi data hasil penilaian angket mengenai pola asuh orang tua dan kedisiplinan belajar anak di Kelurahan Rawang Empat Kecamatan Bandar Petalangan Kabupaten Pelalawan, yang masing-masing tediri dari 10 pertanyaan yang diberikan kepada 23 responden. Adapun data penelitian yang diperoleh adalah sebagai berikut:

a. Data hasil angket pola asuh orang tua (Variabel X)

Dari hasil angket yang telah dikerjakan, diperoleh jumlah nilai 631, dengan skor tertinggi 30 dan skor terendah yaitu 19 .

Interval skor pola asuh orang tua :

$$
\begin{aligned}
\mathrm{R} & =\mathrm{H}-\mathrm{L} \\
& =30-19 \\
& =11 \\
\mathrm{~K} \quad & =1+3.3 \log \mathrm{N} \\
& =1+3.3 \log 23 \\
& =1+3.3(1.36) \\
& =1+4.5 \\
& =5.5 \longrightarrow \text { dibulatkan } 6 \\
\mathrm{I} & =\mathrm{R} \div \mathrm{K} \\
& =11 \div 6 \\
& =1.83 \longrightarrow \text { dibulatkan } 2
\end{aligned}
$$

Keterangan :

$\mathrm{R}=$ Jarak pengukuran $\quad \mathrm{H}=$ nilai tertinggi

$\mathrm{L}=$ nilai terendah $\quad \mathrm{K}=$ Jumlah interval

$\mathrm{I}=$ Lebar interval

Tabel 4 Tabel Distribusi Frekuensi Bergolong Pola Asuh Orang Tua

\begin{tabular}{ccc}
\hline Kelas Interval & Frekuensi & Persentasi \\
\hline $19-20$ & 3 & $13,04 \%$ \\
$21-22$ & 0 & $0 \%$ \\
$23-24$ & 1 & $4,34 \%$ \\
$25-26$ & 2 & $\mathbf{8 , 6 9 \%}$ \\
$27-28$ & 3 & $13,04 \%$ \\
$29-30$ & 14 & $\mathbf{6 0 , 8 6 \%}$ \\
Jumlah & 23 & $\mathbf{1 0 0 \%}$ \\
\hline
\end{tabular}

Berdasarkan hasil perhitungan di atas dapat diketahui bahwa pada pola asuh orang tua terdapat frekuensi terbanyak yaitu pada kelas interval 29 - 30 sebanyak 14 orang responden dengan persentase $60,86 \%$ dan frekuensi terendah pada kelas interval 21 - 22 sebanyak 0 responden dengan persentase $0 \%$.

1) Mencari rata-rata dan standar deviasi

a) Rumus yang digunakan untuk menghitung rata-rata adalah: 


$$
\begin{gathered}
\bar{X}=\frac{\sum X}{N} \\
=\frac{631}{23} \\
=27,43
\end{gathered}
$$

b) Mencari standar deviasi

Sedangkan rumus untuk mengetahui deviasi standar adalah:

$$
\begin{aligned}
S & =\sqrt{\frac{\sum f_{i .\left(x_{i-\bar{x})}\right.}}{\sum f_{i}}} \\
& =\sqrt{\frac{271,44}{23}} \\
& =\sqrt{11,80} \\
& =3,44
\end{aligned}
$$

2) Menentukan kualitas variabel

Menentukan kualitas variabel X ( Pola asuh orang tua)

$$
\begin{aligned}
& M+1,5 S D=27.43+(1.5)(3.44)=27.43+5.16=32.59 \\
& M+0,5 S D=27.43+(0.5)(3.44)=27.43+1.72=29.15 \\
& M-0,5 S D=27.43-(0.5)(3.44)=27.43-1.72=25.71 \\
& M-1,5 S D=27.43-(1.5)(3.44)=27.43-5.16=22.27
\end{aligned}
$$

Dari perhitungan data di atas dapat kita kategorikan nilai pola asuh orang tua di peroleh sebagai berikut:

Tabel 5 Kualitas Variabel X (Pola asuh orang tua )

\begin{tabular}{cccc}
\hline Rata-rata & Interval & Kualitas & Kriteria \\
\hline $\mathbf{2 7 , 4 3}$ & 32 ke atas & Sangat baik & Cukup \\
& $29-31$ & Baik & Baik \\
& $\mathbf{2 5}-\mathbf{2 8}$ & Cukup baik & \\
& $22-24$ & Kurang baik & \\
& 21 ke bawah & Sangat Kurang baik & \\
\hline
\end{tabular}

Dari uraian di atas dapat diketahui bahwa pola asuh orang tua dalam kategori "cukup baik", yaitu berada pada interval nilai 25 - 28 dengan nilai 27,43

b. Data hasil angket tingkat kedisiplinan belajar anak sekolah dasar (Variabel Y)

Dari hasil angket yang telah dikerjakan, diperoleh jumlah nilai 532 , dengan skor tertinggi 28 dan skor terendah yaitu 15 .

Interval skor kedisiplinan belajar anak :

$\mathrm{R}=\mathrm{H}-\mathrm{L}$ 
Al-Ishlah: Jurnal Pendidikan - ISSN: 2087-949o (p); 2597-940X (e)

Vol. 12, No. 2 (2020)

$$
\begin{aligned}
& =28-15 \\
& =13 \\
\mathrm{~K} & =1+3.3 \log \mathrm{N} \\
& =1+3.3 \log 23 \\
& =1+3.3(1.36) \\
& =1+4.5 \\
& =5.5 \\
\mathrm{I} & =\mathrm{R} \div \mathrm{K} \\
& =13 \div 6 \\
& =2.16
\end{aligned}
$$

Keterangan :

$$
\begin{array}{ll}
\mathrm{R}=\text { jarak pengukuran } & \mathrm{H}=\text { Nilai tertinggi } \\
\mathrm{L}=\text { Nilai terendah } & \mathrm{K}=\text { jumlah interval } \\
\mathrm{I}=\text { lebar interval } &
\end{array}
$$

Tabel 6 Tabel Distribusi Frekuensi Bergolong Tingkat Kedisiplinan Belajar Anak

\begin{tabular}{ccc}
\hline Kelas Interval & Frekuensi & Persentasi \\
\hline $15-16$ & 3 & $13,04 \%$ \\
$17-18$ & 0 & $0 \%$ \\
$19-20$ & 1 & $4,34 \%$ \\
$21-22$ & 3 & $13,04 \%$ \\
$23-24$ & 8 & $34,78 \%$ \\
$25-26$ & 5 & $21,74 \%$ \\
$27-28$ & 3 & $13,04 \%$ \\
Jumlah & 23 & $100 \%$ \\
\hline
\end{tabular}

Berdasarkan hasil perhitungan di atas dapat diketahui bahwa tingkat kedisiplinan belajar anak terdapat frekuensi terbanyak yaitu pada kelas interval 23-24 sebanyak 8 anak dengan persentase 34,78\% dan frekuensi terendah pada kelas interval 17-18 sebanyak 0 anak dengan persentase $0 \%$.

1) Mencari rata-rata standar deviasi

a) Rumus yang digunakan untuk menghitung rata-rata adalah:

$$
\begin{aligned}
\bar{Y} & =\frac{\sum y}{N} \\
& =\frac{532}{23} \\
& =23,13
\end{aligned}
$$

b) Mencari standar deviasi

Sedangkan rumus untuk mencari deviasi standar adalah : 
Vol. 12, No. 2 (2020)

$$
\begin{aligned}
S & =\sqrt{\frac{\sum f_{i .\left(y_{i-} \bar{y}\right)}}{\sum f_{i}}} \\
& =\sqrt{\frac{282,34}{23}} \\
& =\sqrt{12,28} \\
& =3,5
\end{aligned}
$$

2) Menentukan kualitas variabel

Menentukan kualitas Variabel Y ( Kedisiplinan belajar anak )

$$
\begin{aligned}
& M+1,5 S D=23,13+(1,5)(3,5)=23,13+5,25=28,38 \\
& M+0,5 S D=23,13+(0,5)(3,5)=23,13+1,75=24,88 \\
& M-0,5 S D=23,13-(0,5)(3,5)=23,13-1,75=21,38 \\
& M-1,5 S D=23,13-(1,5)(3,5)=23,13-5,25=17,88
\end{aligned}
$$

Dari hasil perhitungan data di atas dapat kita kategorikan nilai kedisiplinan belajar anak diperoleh sebagai berikut :

Tabel 7 Kualitas variabel Y (Tingkat Kedisiplinan Belajar Anak)

\begin{tabular}{cccc}
\hline Rata-rata & Interval & Kualitas & Kriteria \\
\hline $\mathbf{2 3 , 1 3}$ & 28 ke atas & Sangat disiplin & Cukup \\
& $24-27$ & Disiplin & Disiplin \\
& $\mathbf{2 1}-\mathbf{2 3}$ & Cukup Disiplin & \\
$17-20$ & Kurang Disiplin & \\
& 19 ke bawah & Sangat Kurang & \\
& & disiplin & \\
\hline
\end{tabular}

Dari uraian data di atas dapat diketahui bahwa tingkat kedisiplinan belajar anak dalam kategori "cukup disiplin", yaitu berada pada interval 21 - 23 dengan nilai 23,13 .

\section{Analisis Uji Hipotesis}

Analisis ini dilakukan untuk mengetahui ada atau tidaknya hubungan antara pola asuh orang tua dengan kedisiplinan belajar anak sekolah dasar di Kelurahan Rawang Empat Kecamatan Bandar Petalangan Kabupaten Pelalawan. Analisis ini didasarkan pada data pola asuh orang tua (variabel X) data data kedisiplinan belajar anak sekolah dasar di Kelurahan Rawang Empat Kecamatan Bandar Petalangan Kabupaten Pelalawan (variabel Y). Sebelum data dihitung, untuk memeperoleh jawaban atas pertanyaan penelitian maka diajukan hipotesis alternatif $\left(\mathrm{H}_{\mathrm{a}}\right)$ dan Hipotesis Nihil $\left(\mathrm{H}_{0}\right)$ terlebih dahulu, yaitu sebagai berikut :

$\mathrm{H}_{\mathrm{a}}$ : terdapat hubungan yang signifikan antara pola asuh orang tua dengan kedisiplinan belajar anak sekolah dasar di Kelurahan 
Rawang Empat Kecamatan Bandar Petalangan Kabupaten Pelalawan

$\mathrm{H}_{0}$ : tidak terdapat hubungan yang signifikan antara pola asuh orang tua dengan kedisiplinan belajar anak sekolah dasar di Kelurahan Rawang Empat Kecamatan Bandar Petalangan Kabupaten Pelalawan.

Apabila nilai $t_{\text {hitung }}\left(t_{h}\right)$ lebih kecil dari nilai $t_{\text {tabel }}\left(t_{t}\right)$ maka hipotesis diterima, sehingga ada hubungan yang signifikan antara pola asuh orang tua dengan kedisiplinan belajar anak sekolah dasar di Kelurahan Rawang Empat Kecamatan Bandar Petalangan Kabupaten Pelalawan.

Sedangkan apabila nilai $t_{\text {hitung }}\left(t_{h}\right)$ lebih besar atau sama dengan nilai $t_{\text {tabel }}\left(t_{t}\right)$ maka hipotesis ditolak, sehingga tidak ada hubungan yang signifikan antara pola asuh orang tua dengan kedisiplinan belajar anak sekolah dasar di Kelurahan Rawang Empat Kecamatan Bandar Petalangan Kabupaten Pelalawan.

Dalam menganalisis uji hipotesis tersebut, peneliti menggunakan analisis statistik korelasi dengan rumus product moment. Langkah awal dari teknis analisis ini adalah membuat tabel kerja kemudian memasukkan angka-angka tersebut dalam tabel. Dari tabel tersebut kemudian dimasukkan ke dalam tabulasi data (variabel $\mathrm{X}$ dan Y), diketahui :

$$
\begin{array}{ll}
\sum X=631 & \sum Y^{2}=12.584 \\
\sum Y=532 & \sum X Y=14.856 \\
\sum X^{2}=17.577 & \mathrm{~N} \quad=23
\end{array}
$$

Kemudian data tersebut diolah menggunakan rumus statistika dengan memakai korelasi product moment $\left(\mathrm{r}_{\mathrm{xy}}\right)$, sebagai pembuktian diterima atau tidaknya hipotesis yang peneliti ajukan maka peneliti menggunakan dua variabel yaitu pola asuh orang tua (X) dan kedisiplinan belajar anak (Y). Adapun langkahlangkahnya sebagai berikut :

a. Mencari koefisien korelasi variabel $\mathrm{X}$ dan $\mathrm{Y}$ dengan rumus :

$$
\begin{aligned}
& \mathrm{r}_{\mathrm{xy}}=\frac{N \cdot \sum(X \cdot Y)-\left(\sum X\right) \cdot\left(\sum Y\right)}{\left.\sqrt{\left\{\left(N \cdot \sum X^{2}\right.\right.}-\left(\sum X\right)^{2}\right) \cdot\left(N \cdot \sum Y^{2}-\left(\sum Y\right)^{2}\right\}} \\
& r_{x y}=\frac{23(14.586)-(631)(532)}{\left.\sqrt{\left\{23(17.577)-(631)^{2}\right.}\right\}\left\{23(12.584)-(532)^{2}\right\}} \\
& r_{x y}=\frac{341.688-335.692}{\sqrt{(404.271-398.161)(289.432-283.024)}} \\
& r_{x y}=\frac{5.966}{\sqrt{(6.110)(6.408)}} \\
& r_{x y}=\frac{5.966}{\sqrt{39.152 .880}}
\end{aligned}
$$




$$
\begin{aligned}
& r_{x y}=\frac{5 \cdot 966}{6 \cdot 257,23} \\
& r_{x y}=0,95345 \text { dibulatkan } 0,953
\end{aligned}
$$

Besarnya hubungan pola asuh orang tua dengan kedisiplinan belajar anak sekolah dasar di Kelurahan Rawang Empat Kecamatan Bandar Petalangan Kabupaten Pelalawan di peroleh nila $r_{x y}=0,953$ masuk dalam kategori " sangat kuat" pada interval $0,80-1,000$ dilihat dari tabel 1.2 Interprestasi koefisien korelasi nilai $r$ yang terdapat pada bab III.

Dengan hasil perhitungan di atas, dapat dilihat bahwa $r_{\text {hitung }}$ sebesar 0,953 lebih besar dari $r$ tabel sebesar 0,413. Dengan demikian menunjukkan bahwa korelasi tersebut signifikan pada taraf 5\% dan menunjukkan arah korelasi positif.

b. Mencari besarnya kontribusi X terhadap Y

Selanjutnya untuk menyatakan besar kecilnya kontribusi variabel $\mathrm{X}$ terhadap variabel $\mathrm{Y}$ dapat ditentukan dengan rumus koefisien determinan sebagai berikut :

$$
\begin{aligned}
\mathrm{KP} & =\mathrm{r}^{2} \cdot 100 \% \\
& =(0,953)^{2} \cdot 100 \% \\
& =0,908209 \times 100 \% \\
& =90,82 \text { dibulatkan menjadi } 90,8 \%
\end{aligned}
$$

Dimana :

$\mathrm{KP}=$ nilai koefisien determinan

$\mathrm{R}=$ nilai koefisien korelasi

Artinya, pola asuh orang tua (variabel $\mathrm{X}$ ) memberikan kontribusi terhadap tingkat kedisiplinan belajar anak (variabel Y) di Kelurahan Rawang Empat Kecamatan Bandar Petalangan Kabupaten Pelalawan sebesar 90,8\% dan sisanya 9,2\% ditentukan oleh variabel lain.

c. Menguji signifikasi hubungan variabel $\mathrm{X}$ dengan variabel $\mathrm{Y}$

$$
\begin{aligned}
& \mathrm{t}_{\text {hitung }}=\frac{r \sqrt{n-2}}{\sqrt{1-r^{2}}} \\
&=\frac{0,953 \sqrt{23-2}}{\sqrt{1-(0,953)^{2}}} \\
&= \frac{0,953 \times 4,583}{\sqrt{0,0918}} \\
&=\frac{4,368}{0,303} \\
&=14,416
\end{aligned}
$$

d. Mencari derajat kebebasan

$$
\begin{aligned}
\mathrm{dk} & =\mathrm{n}-\mathrm{k} \\
& =23-2
\end{aligned}
$$




\section{$=21$ \\ Analisis Lanjut}

Analisis lanjut digunakan untuk menganalisis hipotesis yang terdapat dalam analisis pendahuluan dan analisis uji hipotesis. Berdasarkan perhitungan analisis uji hipotesis dapat diketahui bahwa dk nya 21. Untuk mengetahui jarak signifikasinya dapat diperoleh melalui tabel nilai distribusi t, baik pada taraf signifikasi $5 \%$ maupun $1 \%$. Jika $t_{\text {hitung }} \geq \mathrm{t}_{\text {tabel }}$ maka hipotesis diterima, dan jika $\mathrm{t}_{\text {hitung }} \leq \mathrm{t}_{\text {tabel }}$ maka hipotesis ditolak.

Dengan memeriksa perhitungan $\mathrm{t}_{\text {tabel }}$ ternyata $\mathrm{dk}$ sebesar 21 menunjukkan angka sebagai berikut:

Table 8 Analisis Uji Hipotesis

\begin{tabular}{lrrrrr}
\hline \multicolumn{1}{c}{ Uji } & $\mathbf{t}_{\text {hitung }}$ & \multicolumn{2}{c}{$\mathbf{t}_{\text {tabel }}$} & Keterangan & Hipotesis \\
\cline { 3 - 4 } Hipotesis & & $5 \%$ & $1 \%$ & & \\
Uji t & $\mathbf{1 4 , 4 1 6}$ & $\mathbf{0 , 4 3 3}$ & $\mathbf{0 , 5 4 9}$ & Signifikan & Diterima \\
\hline
\end{tabular}

Keterangan:

a. Pada taraf signifikansi $5 \% \mathrm{t}_{\text {tabel }}=0,433$

b. Pada taraf signifikansi $1 \% \mathrm{t}_{\text {tabel }}=0,549$

Berdasarkan uji analisis di atas, maka diketahui bahwa naik pada taraf signifikansi $5 \%$ maupun $1 \%$ menunjukkan $t_{\text {hitung }} \geq t_{\text {tabel }}(14,416 \geq 0,433)$ dan $(14,416 \geq 0,549)$ maka $\mathrm{H}_{\mathrm{a}}$ diterima. Dengan demikian hipotesis yang peneliti ajukan yang berbunyi "ada hubungan yang signifikan antara pola asuh orang tua dengan kedisiplinan belajar anak sekolah dasar di Kelurahan Rawang Empat Kecamatan Bandar Petalangan Kabupaten Pelalawan” dapat diterima kebenarannya.

Dari teori di atas yang peneliti gunakan dalam menjelaskan pola asuh orang tua sangat mempengaruhi tingkat kedisiplinan anak-anaknya. Berdasarkan hasil penelitian, hal tersebut berdampak cukup siginifikan. Jika di analisa data dari mulai analisis pendahuluan, analisis uji hipotesis da analisis lanjut dalam paparan di atas, maka pola asuh orang tua dapat diartikan sebagai suatu proses interaksi orang tua, yang meliputi kegiatan dengan anak yang meliputi berbagai kegiatan seperti, membimbing, memelihara, mendidik, serta mendisiplinkan dengan tujuan agar mencapai proses kedewasaan baik itu secara langsung atau tidak langsung sangat berpengaruh.

Sementara pola asuh yang digunakan kebanyakan menggunakan teori Hourlock, Baumrind, Yatim dan Irwanto, Hardy dan Heyes juga Laissez Faire, yang menyatakan bahwa pola asuh demokratis itu lebih fleksibel dan mudah di terapkan untuk antropologi sosial masyarakat Indonesia pada umumnya. Sebagai buktinya, orang tua menggunakan teori Hourlock, Manurung dan Santrock, yang mengatakan bahwa budaya dan keyakinan turut mendominasi dalam 
Al-Ishlah: Jurnal Pendidikan - ISSN: 2087-949o (p); 2597-940X (e)

Vol. 12, No. 2 (2020)

menggunakan pola asuh demokratis. Maka kedisiplinan anak SD dengan pola asuh demokratis masih kurang berhasil dan membawa dampak signifikan, maka mestinya orang tua lebih inovatif dalam memanfaatkan model pola asuh anak SD di sesuaikan dengan psikologi anak. Bisa juga menggunakan pola demokratis, di lain waktu dengan teori lain, tidak mesti monoton model pola asuh demokratis saja, apalagi pada anak usia SD yang terkadang harus sedikit otoriter, agar anak memiliki rasa hormat pada orang tua, berkaitan dengan kedisiplinan dalam meraih prestasi belajar.

\section{SIMPULAN}

Berdasarkan hasil analisis data dan pembahasan dalam kajian tersebut dapat disimpulkan bahwa orang tua di Kecamatan Rawang Empat, Kecamatan Bandar Petalangan, Kabupaten Pelalawan, hampir semuanya mengadopsi pengasuhan demokratis. Pola asuh orang tua yang memiliki anak yang duduk di bangku sekolah dasar di Kelurahan Rawang Empat Kabupaten Pelalawan dalam kategori "cukup baik" yakni terdapat pada kelas interval 25 - 28 dengan nilai rata-rata 27,43 dan standar deviasi 3,44. Sedangkan tingkat kedisiplinan anak sekolah dasar di Kelurahan Rawang Empat Kabupaten Pelalawan dalam kategori "cukup disiplin" yaitu pada interval 21 - 23 dengan nilai rata-rata 23,13 dan standar deviasi 3,50. Terdapat hubungan yang signifikan antara gaya orang tua dan tingkat disiplin anak-anak sekolah rendah di Desa Rawang Empat, Kabupaten Bandar Petalangan, Kabupaten Pelalawan. Dari tabel hasil penelitian dan analisis tentang pola asuh orang tua dengan kedisiplinan anak sekolah dasar di Kelurahan Rawang Empat Kabupaten Pelalawan diperoleh hasil $t_{\text {hitung }}=14,416$ dan $t_{\text {tabel }}$ taraf signifikan $5 \%$ sebesar 0,433 sedangkan $t_{\text {tabel }}$ pada taraf signifikan $1 \%$ sebesar 0,549 . Hal ini berarti hasil $t_{\text {hitung }}$ lebih besar dari $t_{\text {tabel }}$. Dengan begitu dapat disimpulkan semakin baik pola asuh orang tua maka semakin tinggi tingkat kedisiplinan belajar anak.

\section{DAFTAR PUSTAKA}

A.Tabrani Rusyam. (t.th). (2010). Pendidikan Budi Pekerti. Jakarta: PT IntimediaCiptanusantara.

Ahmadi, Abu. (2011). Methodik Khusus Pendidikan Agama (MKPA). Bandung: Armico.

Al. Tridhonanto. (2014). Mengembangkan Pola Asuh Demokratis. Jakarta: PT.Elex Media Komputindo Kelompok Gramedia.

Allen E, Jane dan Marylin Cheryl. (2005).Disiplin Positif. Jakarta: PrestasiPutakaraya.

Atheva, Abi. (2007). Perilaku Baik Sehari-hari. Semarang: CV Aneka Ilmu. 
Al-Ishlah: Jurnal Pendidikan - ISSN: 2087-949o (p); 2597-940X (e)

Vol. 12, No. 2 (2020)

Afiatul, Syifa. M, (2015). Hubungan Pola Asuh Orang Tua Dengan Tingkat Kedisiplinan Siswa Kelas $V$ Mi Annashriyah Kecamatan Lasem Kabupaten Rembang Tahun Ajaran 2014/2015, Fakultas Ilmu Tarbiyah Dan Keguruan Universitas Islam Negeri Walisongo Semarang.

D.Gunarsa, Yulia Singgih. (2009). Asas Asas Psikologi Keluarga Idaman. Jakarta: Bpk Gunung Mulia.

Dariyo, Agoes. (2011). Psikologi Perkembangan Anak Tiga Tahun Pertama. Bandung: PT.Refika Aditama.

Dariyo, Agoes. (2004). Psikologi Perkembangan Dewasa Muda. Jakarta: Grasindo.

Desmita. (2005). Psikologi Pendidikan. Bandung: PT Remaja Rosdakarya.

Edwards, Drew. (2016). Ketika Anak Sulit Diatur. (Bandung: PT Mizan Pustaka. Hardy M. dan Heyes S. (2001). Pengantar Psikologi. Jakarta: Erlangga.

Hasbullah. (2012). Dasar-dasar Ilmu Pendidikan. Jakarta: PT. Raja Grafindo Persada.

Ihsan, Fuad. (2007). Pendidikan dalam Keluarga. Jakarta: Bulan Bintang.

Jihan Filisyamala, Hariyono,\&M. Ramli. Jurnal Pendidikan Bentuk Pola Asuh

Demokratis dalam Kedisiplinan Siswa SD, (Online), 1 (4): 668-672, (Journal.um.ac.id/index.php/jptpp/article/view/6213/2648, diakses 7 Juni 2020

King, Laura. (2010). Psikologi Umum. Jakarta : Salemba Humanika.

Koesoema, Doni. (2007). Pendidikan Karakter. Jakarta: PT.Grasindo.

Lemhannas. (2007). Disiplin Nasional. Jakarta:PT.Balai Pustaka.

Lestari, Rizki., Syahrilfuddin,Hamizi, (2014). Hubungan Pola Asuh Orang Tua Dengan Kedisiplinan Siswa Kelas V Gugus I Hang Nadim Kecamatan Tampan Kota Pekanbaru, Jurnal Pendidikan Dasar.

Moleong, Lexy J.. (2010). Metodologi Penelitian Kualitatif. Bandung: Remaja Rosdakarya.

Musaheri. (2010). Pengantar Pendidikan. Yogyakarta: IRCiSoD.

Maulana, Kiki., (2017). Hubungan Pola Asuh Orang Tua Dan Disiplin Siswa Terhadap Hasil Belajar Pkn Siswa Kelas V Sdn Gugus Mawar Kecamatan Semarang Timur, Jurusan Pendidikan Guru Sekolah Dasar Fakultas Ilmu Pendidikan Universitas Negeri Semarang.

Maliki, Ubungan Pola Asuh Orang Tua Terhadap Disiplin Belajar Siswa Di Smpn 7 Kubung, Jurnal Konseling Dan Pendidikan, 2016. 
Al-Ishlah: Jurnal Pendidikan - ISSN: 2087-949o (p); 2597-940X (e)

Vol. 12, No. 2 (2020)

Nasution dan Nurhalijah. (2000). Peranan Orang Tua dalam Meningkatkan Prestasi Belajar Anak. Yogyakarta: Jakarta Gunung Mulia.

Santrock, J.W. (2005). Life-Span Development: Perkembangan Masa Hidup Jilid I. Jakarta: Erlangga.

Sujarwo, (2016). Pengaruh Pola Asuh Orang Tua Terhadap Kedisiplinan Belajar Siswa Kelas V Sd Segugus Ii Kasihan Bantul Yogyakarta 2015/2016, Program Studi Pendidikan Guru Sekolah Dasar Fakultas Keguruan Dan Ilmu Pendidikan Universitas Pgri Yogyakarta.

Sanuri, Arif. (2006). Membentuk Kecerdasan Anak Sejak Dini. Yogyakarta: ThinkJogjakarta.

Slameto. (2015). Belajar dan Faktor-faktor yang Mempengaruhinya. Jakarta: Rineka Cipta.

Suarsini, Desy. (2013). Pola Asuh Orang Tua, Artikel (online)(http;//desysuar.blogspot.com

Sulistiyowati, Sofchah. (2011). Cara Belajar yang Efektif dan Efisien. Pekalongan:Cinta Ilmu.

Sipayung, Regina., (2017). Pengaruh Pola Asuh Orang Tua Dan Disiplin Belajar Terhadap Hasil Belajar Siswa Sd Kelas V Di Sd Negeri Muara Bolak 4 Kec. Sosorgadong, Lembaga Penelitian Dan Pengabdian Pada Masyarakat (Lppm) Fakultas Keguruan Dan Ilmu Pendidikan Universitas Katolik Santo Thomas Sumatera Utara Medan.

Suprijanto. (2010). Pendidikan orang dewasa. Jakarta: PT. Bumi Aksara.

Sari, Rima Devita., (2015). Hubungan Pola Asuh Orang Tua Dengan Disiplin Belajar Siswa Kelas IV Dan V Sekolah Dasar Negeri Se-Gugus I Sidoarum Kecamatan Godean Kabupaten Sleman, Program Studi Pendidikan Guru Sekolah Dasar Jurusan Pendidikan Sekolah Dasar Fakultas Ilmu Pendidikan Universitas Negeri Yogyakarta September.

Thoha, chabib. (2010). Kapita Selekta Pendidikan Islam. Yogyakarta: Pustaka pelajar (IKAPI). 